\title{
Development and quality evaluation of iron rich products
}

\author{
T. N. Khan and J. P. Nerlekar
}

Four different iron rich products namely kranky noodles, crunchy ball, nutri grans and nutri ribbon were developed to combat iron deficiency anaemia utilizing locally available, low cost and food stuffs rich in iron content. Developed iron rich products were evaluated organoleptically and nutrient content was determined. The periodical acceptability, nutrient content and microbial content was evaluated at 0,3 and 6 months of storage period. Among the five developed iron rich products the iron content of developed product was in the range of $14.60 \mathrm{mg}$ to $17.20 \mathrm{mg} / 100 \mathrm{~g}$. The results of storage study indicated that the developed products were acceptable while microbial content increased but it was in the safe range.

Key Words : Iron rich products, Anaemia

How to cite this article : Khan, T.N. and Nerlekar, J.P. (2020). Development and quality evaluation of iron rich products. Food Sci. Res. J., 11(2): 186-188, DOI : 10.15740/HAS/FSRJ/11.2/186-188.Copyright@ 2020: Hind Agri-Horticultural Society.

T.N. Khan, Department of Food Science and Nutriton, College of Community Science, Vasantrao Naik Marathwada Krishi Vidyapeeth, Parbhani (M.S.) India

Email: k_naheed@rediffmail.com

Associate Authors' :

J.P. Nerlekar, Department of Food Science and Nutriton, College of Community Science, Vasantrao Naik Marathwada Krishi Vidyapeeth,

Parbhani (M.S.) India 